\title{
A UNIVERSIDADE E A DIVERSIDADE: REVISÃO INTEGRATIVA DA LITERATURA
}

\author{
UNIVERSIDAD Y DIVERSIDAD: REVISIÓN INTEGRATIVA DE LA LITERATURA \\ UNIVERSITY AND DIVERSITY: INTEGRATIVE LITERATURE REVIEW
}

\author{
Letícia Cunha Franco ${ }^{1}$ \\ Thais Dias Venâncio Ferreira ${ }^{2}$ \\ Matheus Henrique Rodrigues da Silva Santos ${ }^{3}$ \\ William Koga Silva Filho ${ }^{4}$
}

\begin{abstract}
RESUMO: Objetivo: Evidenciar a partir da literatura nacional, a produção científica na área temática "Universidade e a Diversidade". Método: Revisão integrativa da literatura, na base de dados SciELO (Scientific Electronic Library Online). Resultados: foram encontrados 433 estudos, e selecionados 29. O maior número de publicações, ocorreu no período entre 2018 e 2020 $(n=51,7 \%)$, sendo mais frequente as análises documentais $(n=24,1 \%)$, e de abordagem qualitativa $(n=17,2 \%)$. As revistas que mais publicaram estudos, foram da área da educação $(n=65,5 \%)$. E dentre os subtemas, àqueles mais estudados, estavam relacionados à diversidade sexual e de gênero $(\mathrm{n}=27,5 \%)$, e políticas de cotas $(\mathrm{n}=24,1 \%)$. Conclusão: há necessidade do despertar, de todas as ciências, para reflexões acerca da abordagem das diversidades no ambiente universitário, para maior sensibilização ao estado da arte, redução das desigualdades de acesso, qualidade da permanência em âmbito da saúde integral, e do processo de ensino e aprendizagem, e melhor qualidade de vida.
\end{abstract}

PALAVRAS-CHAVE: Universidade. Educação. Diversidade.

RESUMEN: Objetivo: Destacar, a partir de la literatura nacional, la producción científica en el área temática "Universidad y Diversidad". Método: revisión integradora de literatura en la base de datos SciELO (Scientific Electronic Library Online). Resultados: Se encontraron 433 estudios y se seleccionaron 29. El mayor número de publicaciones se produjo en el período entre $2018 \mathrm{y}$ $2020(\mathrm{n}=51,7 \%)$, siendo más frecuentes los análisis documentales $(\mathrm{n}=24,1 \%)$, y enfoque cualitativo $(n=17,2 \%)$. Las revistas que más estudios publicaron fueron las del área de educación $(\mathrm{n}=65,5 \%)$. Y entre los subtemas, los más estudiados, estaban relacionados con la diversidad sexual y de género $(n=27,5 \%)$, y las políticas de cuotas $(n=24,1 \%)$. Conclusión: existe la necesidad de despertar, desde todas las ciencias, para reflexionar sobre el abordaje de la diversidad en el ámbito universitario, para sensibilizar sobre el estado del arte, reducir las desigualdades en el acceso, la calidad de permanencia en el área de salud integral y el proceso de enseñanza y

1 Doutora em Enfermagem. Universidade Federal de Catalão, Catalão, Goiás, Brasil. E-mail: leticiafranco2or8@ufg.br.

${ }^{2}$ Graduada em Letras. Universidade Federal de Catalão, Catalão, Goiás, Brasil.

3 Acadêmico de Enfermagem. Universidade Federal de Catalão, Catalão, Goiás, Brasil.

${ }_{4}^{4}$ Graduado em Administração. Universidade Federal de Catalão, Catalão, Goiás, Brasil. 
aprendizaje, y mejor calidad de vida.

PALABRAS-CLAVE: Universidad. Educación. Diversidad.

ABSTRACT: Objective: To highlight, based on national literature, scientific production in the thematic area "University and Diversity". Method: Integrative literature review in the SciELO database (Scientific Electronic Library Online). Results: 433 studies were found, and 29 were selected. The largest number of publications occurred in the period between 2018 and $2020(\mathrm{n}=$ $51.7 \%)$, with documentary analyzes being more frequent $(\mathrm{n}=24.1 \%)$, and of qualitative approach $(\mathrm{n}=17.2 \%)$. The magazines that published the most studies were in the area of education $(\mathrm{n}=$ 65.5\%). And among the sub-themes, those most studied, were related to sexual and gender diversity $(n=27.5 \%)$, and quota policies $(n=24.1 \%)$. Conclusion: there is a need to awaken, from all sciences, to reflect on the approach to diversity in the university environment, to raise awareness of the state of the art, reduce inequalities in access, quality of permanence within the scope of integral health, and the process of teaching and learning, and better quality of life.

KEYWORDS: University. Education. Diversity.

\section{INTRODUÇÃO}

A Diversidade reflete a pluralidade, heterogeneidade e variedade do Ser e da Sociedade. E, também, pode ser encontrada na comunhão de contrários ou diferentes, e na tolerância mútua (HUISMAN, 1995). Todavia, no respeito à Diversidade, reflete-se em Dar Espaço, Escuta, Voz

e Garantia do Direito, ao Ser, na sua diferença. E a Educação na Diversidade, instiga, à transformar a sociedade e nós mesmos, priorizando o respeito entre todos, e o trabalho de valores e conceitos (HUISMAN, 1995), como: oportunizar, tolerância, diversidade, identidade, liberdade, igualdade, inclusão, cidadania, empatia e paz.

Outrossim, a universidade tem responsabilidade na transformação da sociedade, instigando à liberdade de expressão e reflexão/discussão democrática, bem como de potencializar o emergir de novas ciências, disciplinas e saberes, todas, fundamentadas na garantia e exercício dos Direitos Humanos. Porém, o Estado brasileiro, historicamente, contribuiu para o fortalecimento de um conjunto dinâmico de valores, normas e crenças, responsáveis por reduzir à figura do outro (considerado estranho, inferior, pecador, doente, pervertido, criminoso ou contagioso) todos/as que não se sintonizassem com os componentes valorizados pelos arsenais normativos centrados no adulto, masculino, branco, heterossexual, burguês, sem impedimentos físicos, mentais ou sensoriais. Todavia o classismo, sexismo, heterossexismo, racismo, capacitismo (às pessoas com deficiência) e outras formas de preconceito e discriminação, representam um problema educacional, e afetam a qualidade da educação de todas as pessoas (LOPES; JUNQUEIRA, 2014).

Assim, a educação de qualidade, exige o enfrentamento de preconceitos e discriminação, 
para harmonização entre as diferenças e a diversidade (LOPES; JUNQUEIRA, 2014). E a diferença, não é sempre um marcador de hierarquia e opressão, mas uma questão contextualmente contingente de saber se a diferença resulta em desigualdade, exploração e opressão ou em igualitarismo, diversidade e formas democráticas de agência política (BRAH, 2006). Com isso, é indispensável atentarmos para os limites de determinadas medidas que, embora aparentemente generosas quanto ao "respeito à diferença" ou à "aceitação da diversidade", não se mostram dispostas a romper os seus compromissos com uma educação normalizadora, (re)produtora e reiteradora dos ditames do classismo, da branquitude, da heteronormatividade, e da corponormatividade (LOPES; JUNQUEIRA, 2014).

E, a experiência prática no ambiente universitário, nos traz reflexão, da incipiência ora ausência de discussões acerca das diversidades, especialmente nas ciências que, ainda, se arraigam em tradicionalismo, minimizando as potencialidades de discussão e construção de saberes, na vivência universitária. Assim, evidencia-se a necessidade iminente, de potencialização de abordagens com foco nas diversidades, na universidade, e consequentemente no aumento das produções técnico-científicas, que possam fortalecer o conhecimento prévio, a construção de novos saberes e modos de vida harmonizados nas diversidades e diferenças. Portanto, o objetivo desta pesquisa, foi evidenciar, e caracterizar, a partir da literatura nacional, a produção científica na área temática "Universidade e a Diversidade".

\section{Método}

Foi realizada revisão integrativa da literatura nacional, acerca da produção científica na área temática "Universidade e a Diversidade". A coleta e análise dos dados, foi realizada no mês de outubro de 2020, por meio de etapas, sendo: na $\mathrm{I}^{\underline{a}}$ etapa, a pesquisa por combinação de descritores, com verificação da disponibilidade do texto (artigo) completo, em idioma português, e com até io anos da publicação. Posteriormente, na 2ª etapa, procedeu-se a análise do título e assunto principal. E conseguinte, na $3^{\underline{a}}$ etapa, executada a análise dos resumos, e leitura dos artigos selecionados, observando os critérios de inclusão, para ratificação ou exclusão, de acordo com o objetivo do estudo, e exclusão por duplicidade. Figura I.

\section{Resultados e Discussão}

Considerando as estratégias de busca e os critérios de elegibilidade dos estudos (na primeira etapa de investigação) foram incluídos 433 estudos. Com isso, partiu-se à análise do título e assunto principal, totalizando 143 estudos. Por fim, diante da leitura e análise dos artigos, foram selecionadas 29 publicações. Figura I.

Figura I. Fluxograma de coleta e análise dos dados. Catalão, Goiás, Brasil, 2020. 


\section{Estratégia de busca}

Combinação de descritores; verificação da disponibilidade do texto completo; seleção do idioma, ano de publicação e tipo de estudo.

Universidade e Diversidade $(n=103)$

Educação e Diversidade $(n=330)$

Total de Estudos: 433

-

Análise do título e assunto principal

Universidade e Diversidade ( $n=17)$

Educação e Diversidade $(n=126)$

Total de Estudos: 143

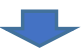

Leitura e análise dos resumos, e artigos selecionados; e aplicados os critérios de inclusão e exclusão.

Universidade e Diversidade ( $n=16)$

Educação e Diversidade ( $n=13)$

Total de Estudos: 29

Fonte: Elaboração dos autores, 2020.

O maior número de publicações, ocorreu no período entre 2018 e $2020(\mathrm{n}=51,7 \%)$. Destas, o tipo de estudo mais frequente, foi o de análise documental $(n=24,1 \%)$, seguido de estudos de abordagem qualitativa $(n=17,2 \%)$. As revistas que mais publicaram estudos na temática investigada, foram aquelas da área da educação $(n=65,5 \%)$. E dentre os subtemas da área (aqueles mais estudados) estavam relacionados à diversidade sexual e de gênero $(n=27,5 \%)$, e políticas de $\operatorname{cotas}(\mathrm{n}=24, \mathrm{1} \%)$. Quadro I.

O período com maior número de publicações $(\mathrm{n}=5 \mathrm{I}, 7 \%)$, nos instiga à reflexão do cenário político-econômico e educacional, entre 2018 e 2020. E nos inquieta, que neste período, não houveram avanços significativos, nas políticas para inclusão e diversidades no cenário universitário, sendo a Lei no 12.71I/12, conhecida como Lei de Cotas, que trata da distribuição de vagas nas universidades, à negros, pardos, indígenas, quilombolas, pessoas com deficiência, e ou vulnerabilidade social (BRASIL, 2012), e a Lei no 13.146/2015, que institui a Lei Brasileira de Inclusão da Pessoa com Deficiência (Estatuto da Pessoa com Deficiência), as expressões mais recentes na transformação de paradigmas, no cenário nacional (BR.ASIL, 2015).

Todavia, refletimos que a possibilidade de retrocesso, ou estagnação nas políticas educacionais e de direitos humanos, podem impactar no aumento das produções científicas no período supracitado, considerando que na construção do conhecimento, revelam-se insatisfações, inquietações, possibilidades, e caminhos para a garantia da cidadania, e rompimento das desigualdades.

Ademais, a maior parte dos estudos $(\mathrm{n}=24, \mathrm{r} \%)$, caracterizou-se em análise documental, 
com isso, visualizamos as possibilidades, que confere a este tipo de estudo. A pesquisa documental, abrange análise de uma variedade ampla de materiais, como documentos oficiais de um governo, cartas, relatórios, vídeos, fotos, jornais, revistas, entrevistas, matérias de jornais, e demais. Outra característica deste tipo de estudo, é a ausência de intervenção analítica anterior, com isto, os materiais podem sofrer reelaboração de acordo com os objetivos da pesquisa. E as informações contidas nessas fontes de pesquisa documental, possibilitam análise qualitativa do objeto de estudo (LOPES, 2006).

É evidente, que as análises documentais contribuem para a ampliação da reflexão do cenário de discussões e construções da temática, visto que quanto maior a variedade de fontes de dados, maior será a possibilidade de alcance do estado da arte, e da tradução da amplitude do exercício da diversidade e cidadania.

E, observando que a maior parte dos estudos foram publicados na área da educação $(\mathrm{n}=65,5 \%)$, questionamos a necessidade de impulsionar as discussões acerca das diversidades, especialmente nas ciências que, ainda, se arraigam em tradicionalismo, minimizando as potencialidades de discussão e construção de saberes, na vivência universitária. Os resultados (Quadro I) demonstram, a necessidade de reestruturação das políticas pedagógicas e diretrizes curriculares, de maneira que ampliem as possibilidades de inserção e discussão da temática, e sensibilize para a transformação de comportamentos, atitudes, e ações, assim, aproximando a ciência da realidade vivida.

Além de que, dentre os subtemas da área temática estudada, àqueles que mais emergiram, estavam relacionados à diversidade sexual e de gênero $(n=27,5 \%)$, e políticas de cotas $(n=24,1 \%)$. (Quadro I). Visto isso, refletimos que os estudos acerca das diversidades, ainda são incipientes, frente a amplitude do conceito, assim, nos despertando, para o quão relevante é a necessidade de ampliação das discussões e compartilhamento de definições, conceitos e paradigmas da área, no ambiente universitário. E neste sentido, poderemos visualizar a possibilidade de fortalecimento das políticas educacionais para redução de desigualdades, vulnerabilidades, e respeito mútuo.

Quadro I. Caracterização dos estudos selecionados, de acordo com título, ano, periódico, tipo de estudo, e conclusões. Catalão, Goiás, Brasil, 2020.

\begin{tabular}{|c|l|l|l|l|l|}
\hline \multicolumn{2}{|l|}{ Descritor: Universidade e Diversidade } & Ano & Periódico & $\begin{array}{l}\text { Tipo de } \\
\text { Estudo }\end{array}$ & Conclusão \\
\hline & Título & $\begin{array}{l}\text { Uma análise marxiana da } 2020 \\
\text { política de cotas no ensino } \\
\text { superior público brasileiro. }\end{array}$ & $\begin{array}{l}\text { Revista } \\
\text { Katálysis }\end{array}$ & $\begin{array}{l}\text { Revisão } \\
\text { bibliográfica }\end{array}$ & $\begin{array}{l}\text { A pseudoigualdade burguesa nãa } \\
\text { considera o acesso } \\
\text { historicamente negado da } \\
\text { população negra aos bens e à } \\
\text { riqueza socialmente produzida. }\end{array}$ \\
\hline
\end{tabular}




\begin{tabular}{|c|c|c|c|c|c|}
\hline & & & & & $\begin{array}{l}\text { Por isso, é necessário, outra } \\
\text { forma de acesso, que se vincule a } \\
\text { outro tipo de universalidade e } \\
\text { que, assim, contemple uma } \\
\text { universalidade a partir da } \\
\text { diversidade e da desigualdade, } \\
\text { pois, sob a ótica da igualdade, a } \\
\text { desigualdade permanece. }\end{array}$ \\
\hline 2. & $\begin{array}{l}\text { Análise Descritiva do Tema } \\
\text { Deficiência nos Currículos de } \\
\text { Graduação da Universidade } \\
\text { Federal do Rio Grande do } \\
\text { Norte. }\end{array}$ & 2019 & $\begin{array}{l}\text { Rev. bras. } \\
\text { educ. espec. }\end{array}$ & $\begin{array}{l}\text { Análise } \\
\text { documental }\end{array}$ & $\begin{array}{l}\text { Foi identificada, oportunidades } \\
\text { de melhoria nos currículos de } \\
\text { graduação, por meio do aumento } \\
\text { da quantidade e da diversidade } \\
\text { de tipos de deficiência e temas } \\
\text { abordados nos cursos. E as } \\
\text { análises e visualizações de } \\
\text { informações, poderiam ser } \\
\text { aprimoradas, com o apoio de } \\
\text { sistemas computacionais de } \\
\text { gestão acadêmica, como o } \\
\text { Sistema Integrado de Gestão de } \\
\text { Atividades Acadêmicas - } \\
\text { SIGAA. }\end{array}$ \\
\hline 3. & $\begin{array}{l}\text { Provocações pós-coloniais à } \\
\text { formação em psicologia. }\end{array}$ & 2019 & $\begin{array}{l}\text { Psicologia } \\
\text { Sociedade }\end{array}$ & Pesquisa-ação & $\begin{array}{l}\text { O questionamento da } \\
\text { objetividade, neutralidade e } \\
\text { universalidade da ciência, coloca } \\
\text { em discussão a naturalização da } \\
\text { desigualdade exclusão social. A } \\
\text { reflexão da descolonialidade, } \\
\text { instiga ao denunciativo, das } \\
\text { violências epistêmicas que nos } \\
\text { constituem, e imaginativa das } \\
\text { transformações que temos de } \\
\text { realizar para acolher a } \\
\text { diversidade epistêmica em um } \\
\text { mundo pluriversal. }\end{array}$ \\
\hline 4. & $\begin{array}{l}\text { Transitando entre universidade } \\
\text { e trabalho: trajetórias desiguais } \\
\text { e políticas afirmativas. }\end{array}$ & 2019 & $\begin{array}{l}\text { Cadernos } \\
\text { Pesquisa }\end{array}$ & Pesquisa-ação & $\begin{array}{l}\text { O diploma de prestígio, } \\
\text { transforma a qualidade das } \\
\text { trajetórias dos que, a eles têm } \\
\text { acesso, livrando-os das } \\
\text { vicissitudes que atingem a } \\
\text { grande maioria dos jovens } \\
\text { brasileiros, mas, ele não } \\
\text { consegue eludir as diferenças, } \\
\text { entre os que precisaram recorrer } \\
\text { à ação afirmativa, para } \\
\text { ingressar numa instituição } \\
\text { altamente competitiva. E disso } \\
\text { dão prova, as desigualdades } \\
\text { salariais, que reaparecem nos } \\
\text { primeiros anos da carreira } \\
\text { profissional. }\end{array}$ \\
\hline
\end{tabular}




\begin{tabular}{|c|c|c|c|c|c|}
\hline 5. & $\begin{array}{l}\text { A incorporação da temática de } \\
\text { gênero e diversidade na } \\
\text { academia: por uma ecologia de } \\
\text { saberes na universidade. }\end{array}$ & 2018 & $\begin{array}{l}\text { Educar } \\
\text { Revista }\end{array}$ & $m$ Retrospectivo & $\begin{array}{l}\text { Há necessidade de ampliar o } \\
\text { número de disciplinas que } \\
\text { incluem a temática no currículo } \\
\text { dos cursos. Com isso, é } \\
\text { necessário, aumentar a } \\
\text { contratação de docentes que } \\
\text { atuam nessas áreas, e fomentar } \\
\text { mudanças curriculares nos } \\
\text { cursos. }\end{array}$ \\
\hline 6. & $\begin{array}{l}\text { Políticas públicas de Ação } \\
\text { Afirmativa para indígenas na } \\
\text { Universidade Estadual de Mato } \\
\text { Grosso do Sul: a visão dos } \\
\text { implementadores. }\end{array}$ & 2018 & Pro-Posições & Retrospectivo & $\begin{array}{l}\text { São necessários avanços, } e \\
\text { mecanismos que garantam a } \\
\text { inclusão, e um aparato que } \\
\text { assegure condições minimas de } \\
\text { permanência. }\end{array}$ \\
\hline 7. & $\begin{array}{l}\text { Fundamentos epistemológicos da } \\
\text { matriz institucional dos novos } \\
\text { modelos de educação superior no } \\
\text { brasil: uma abordagem } \\
\text { qualitativa dos documentos } \\
\text { institucionais da universidade } \\
\text { federal do ABC. }\end{array}$ & 2017 & $\begin{array}{l}\text { Educação } \\
\text { Sociedade }\end{array}$ & $\begin{array}{l}\text { Análise } \\
\text { Documental }\end{array}$ & $\begin{array}{l}\text { A interdisciplinaridade } \\
\text { inclusão da diversidade, tal como } \\
\text { as linhas paralelas, são conceitos } \\
\text { que não se encontram; a ruptura } \\
\text { com a tradição deveria ser mais } \\
\text { profunda, propondo outros } \\
\text { conceitos mais ajustados à } \\
\text { diversidade cultural } e \\
\text { epistemológica. }\end{array}$ \\
\hline 8. & $\begin{array}{l}\text { Da crítica à política: Tensões } \\
\text { entre reconhecimento e } \\
\text { democracia racial na política de } \\
\text { cotas da UFRGS. }\end{array}$ & 2017 & $\begin{array}{c}\text { Revista de } \\
\text { Ciências Sociais }\end{array}$ & $\mid \begin{array}{l}\text { Análise } \\
\text { Documental }\end{array}$ & $\begin{array}{l}\text { Do ponto de vista da diversidade } \\
\text { étnico-racial, houve importantes } \\
\text { avanços redistributivos, desde a } \\
\text { implementação das cotas até o } \\
\text { momento, mas ainda é desafio, } \\
\text { que os indivíduos negros sejam } \\
\text { igualmente reconhecidos. }\end{array}$ \\
\hline 9. & $\begin{array}{l}\text { Educar para a diversidade: } \\
\text { gênero e sexualidade segundo a } \\
\text { percepção de estudantes e } \\
\text { supervisoras do programa } \\
\text { institucional de bolsa de } \\
\text { iniciação à docência(UFSM). }\end{array}$ & 2015 & $\begin{array}{l}\text { Revista da } \\
\text { Educação Física }\end{array}$ & la Transversal & $\begin{array}{l}\text { Foi evidenciado, associação } \\
\text { entre os conceitos de gênero e } \\
\text { sexualidade, cujas explicitações } \\
\text { mantêm forte relação com } \\
\text { aspectos biológicos do corpo, e } \\
\text { estão assentadas fortemente, em } \\
\text { heteronormativas. }\end{array}$ \\
\hline Io. & $\begin{array}{l}\text { Intercâmbios educacionais e } \\
\text { diversidade } \\
\text { implicações para o ensino de } \\
\text { português para falantes de } \\
\text { outras línguas. }\end{array}$ & 2014 & \begin{tabular}{|l}
\multicolumn{1}{|c|}{ Revista } \\
Brasileira \\
Linguística \\
Aplicada
\end{tabular} & deQualitativo & $\begin{array}{l}\text { Há necessidade de novas } \\
\text { configurações nas práticas } \\
\text { pedagógicas, e em adaptações no } \\
\text { espaço físico escolar, bem como, } \\
\text { de despertar sensibilidade para } \\
\text { as questões culturais } e \\
\text { interculturais. }\end{array}$ \\
\hline II. & $\begin{array}{l}\text { O desafio da convivência: } \\
\text { assessoria de diversidade e apoio } \\
\text { aos cotistas (2004-2008). }\end{array}$ & 2013 & $\begin{array}{l}\text { Psicologia: } \\
\text { Ciência } \\
\text { Profissão }\end{array}$ & Qualitativo & $\begin{array}{l}\text { Os estudantes cotistas, } \\
\text { referenciam o Centro de } \\
\text { Convivência Negra (CCN), } \\
\text { como um espaço de formação de } \\
\text { identidade negra, havendo aí um }\end{array}$ \\
\hline
\end{tabular}




\begin{tabular}{|c|c|c|c|c|c|}
\hline & & & & & $\begin{array}{l}\text { processo de identificação pessoal } \\
\text { e social; O CNN fomenta } \\
\text { debates públicos e na sua } \\
\text { receptividade a diferentes } \\
\text { dimensões da diversidade, além } \\
\text { da etnicorracial. }\end{array}$ \\
\hline I2. & $\begin{array}{l}\text { Desempenho dos candidatos no } \\
\text { vestibular e o sistema de cotas } \\
\text { na UERJ. }\end{array}$ & 2012 & \begin{tabular}{|l}
\multicolumn{1}{|c|}{ Ensaio: } \\
Avaliação \\
Políticas \\
Públicas \\
Educação
\end{tabular} & Análise & $\begin{array}{l}\text { Observa-se, que a influência } \\
\text { dominante sobre o desempenho } \\
\text { no vestibular, está relacionada à } \\
\text { renda familiar. }\end{array}$ \\
\hline 13. & $\begin{array}{l}\text { Estratégias de pesquisa em } \\
\text { contextos de diversidade } \\
\text { cultural: entrevistas de listagem } \\
\text { livre, entrevistas r com } \\
\text { informantes-chave e grupos } \\
\text { focais. }\end{array}$ & 2012 & $\begin{array}{c}\text { Estudos } \\
\text { Psicologia }\end{array}$ & $\begin{array}{l}\text { Quanti- } \\
\text { qualitativo }\end{array}$ & $\begin{array}{l}\text { As estratégias de pesquisa, como } \\
\text { entrevistas de listagem livre, } \\
\text { entrevistas com informantes- } \\
\text { chave e grupos focais, facilitam } \\
\text { a compreensão do universo } \\
\text { cultural do grupo pesquisa, e } \\
\text { promovem uma participação } \\
\text { mais ativa dos participantes no } \\
\text { processo de pesquisa. Porém, é } \\
\text { necessários cuidado, na } \\
\text { combinações de métodos. }\end{array}$ \\
\hline I4. & $\begin{array}{l}\text { Demandas de docentes do ensino } \\
\text { superior para a formação de } \\
\text { alunos com deficiência. }\end{array}$ & 2012 & \begin{tabular}{|l}
\multicolumn{1}{|c|}{ Revista } \\
Brasileira \\
Estudos \\
Pedagógicos
\end{tabular} & Quantitativo & $\begin{array}{l}\text { Há necessidade instituir um } \\
\text { serviço de apoio à comunidade, } \\
\text { congregue as ações existentes, } \\
\text { especialmente, aquelas } \\
\text { relacionadas à inclusão social, } \\
\text { baseada em atitudes favoráveis à } \\
\text { diversidade humana. }\end{array}$ \\
\hline 15 . & $\begin{array}{l}\text { A experiência do professor } \\
\text { orientador de estudante } \\
\text { indígena em enfermagem. }\end{array}$ & $20 I I$ & $\begin{array}{l}\text { Acta Paulista } \\
\text { de Enfermagem }\end{array}$ & $\int_{\text {Relato }}^{\text {experiência }}$ & $\begin{array}{l}\text { A experiência para atuar como } \\
\text { Professor Orientador teve como } \\
\text { desafio a diversidade cultural em } \\
\text { relação aos saberes do cuidado. } \\
\text { A comunicação terapêutica foi } \\
\text { um instrumento efetivo no } \\
\text { processo. }\end{array}$ \\
\hline I6. & $\begin{array}{l}\text { Discursos sobre } \\
\text { homossexualidade e gênero na } \\
\text { formação docente em biologia. }\end{array}$ & 2010 & Pro-Posições & Reflexão & $\begin{array}{l}\text { Foi observado, rejeiçãa de } \\
\text { posições preconceituosas acerca } \\
\text { das minorias sexuais e de gênero. } \\
\text { Porém, também foi evidenciado, } \\
\text { que a noção da homossexualidade } \\
\text { como algo contagioso permanece, } \\
\text { e a indiferença e o desinteresse } \\
\text { criam obstáculos para uma } \\
\text { melhor aceitação da diversidade } \\
\text { sexual. }\end{array}$ \\
\hline \multicolumn{6}{|c|}{ Descritor: Educação e Diversidade } \\
\hline I7. & $\begin{array}{l}\text { Preconceito contra Diversidade } \\
\text { Sexual e de Gênero, entre }\end{array}$ & 2020 & $\begin{array}{c}\text { Revista } \\
\text { Brasileira }\end{array}$ & Quantitativo & $\begin{array}{l}\text { Foi evidenciado que pelo menos } \\
60 \% \text { dos estudantes, }\end{array}$ \\
\hline
\end{tabular}




\begin{tabular}{|c|c|c|c|c|c|}
\hline & 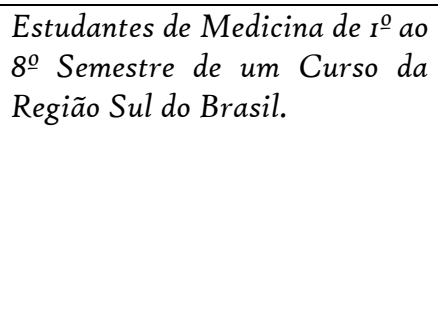 & & $\begin{array}{l}\text { Educação } \\
\text { Médica }\end{array}$ & & $\begin{array}{l}\text { apresentaram atitude negativa } \\
\text { frente às pessoas LGBT, com a } \\
\text { margem desse percentual ser } \\
\text { ainda maior em função de } \\
\text { variáveis como: o preconceito } \\
\text { velado; e o comportamento mais } \\
\text { negativo, em relação às pessoas } \\
\text { transexuais. }\end{array}$ \\
\hline I8. & $\begin{array}{l}\text { Formação de professores para a } \\
\text { justiça social: uma revisão de } \\
\text { estudos empíricos. }\end{array}$ & 2020 & $\begin{array}{l}\text { Educação } \\
\text { Revista }\end{array}$ & $\begin{array}{l}\text { em Revisão } \\
\text { Bibliográfica }\end{array}$ & $\begin{array}{l}\text { Os resultados mostram, que as } \\
\text { formações de professores para a } \\
\text { justiça social, se fundamentam } \\
\text { em pedagogias de resistência, de } \\
\text { caráter social e transformativo, } \\
\text { para além de implicarem uma } \\
\text { reflexão sobre a diversidade em } \\
\text { diferentes níveis, sobre a } \\
\text { educação multicultural e sobre as } \\
\text { especificidades dos contextos } \\
\text { educativos, exigindo dos } \\
\text { formandos grande senso crítico. }\end{array}$ \\
\hline 19. & $\begin{array}{l}\text { Mulheres negras na história da } \\
\text { enfermagem: a competência } \\
\text { cultural na trajetória de Maria } \\
\text { Barbosa Fernandes. }\end{array}$ & 2020 & $\begin{array}{l}\text { Revista } \\
\text { Brasileira } \\
\text { Enfermagem }\end{array}$ & delocumental & $\begin{array}{l}\text { O pareamento da temática da } \\
\text { mulher negra na enfermagem ao } \\
\text { referencial de Competência } \\
\text { Cultural, consiste em um convite } \\
\text { à valorização da diversidade na } \\
\text { profissão e à busca de avançar } \\
\text { em direção ao cuidado } \\
\text { comprometido com a superação } \\
\text { de desigualdades, por meio de } \\
\text { práticas inclusivas e cuidados } \\
\text { culturalmente sensíveis. }\end{array}$ \\
\hline 20. & $\begin{array}{l}\text { A População Transgênero sob o } \\
\text { Olhar da Bioética: Um } \\
\text { Panorama dos Currículos de } \\
\text { Graduação e dos Cursos de } \\
\text { Bioética das Escolas Médicas do } \\
\text { Estado de São Paulo. }\end{array}$ & 2020 & $\begin{array}{l}\text { Revista } \\
\text { Brasileira } \\
\text { Educação } \\
\text { Médica }\end{array}$ & de Exploratório & $\begin{array}{l}\text { A evidente falta de conteúdo } \\
\text { formativo voltado à temática } \\
\text { trans nas escolas médicas, pode } \\
\text { dificultar a busca por um } \\
\text { atendimento mais digno dentro } \\
\text { da rede de atenção à saúde e o } \\
\text { combate à transfobia. A partir } \\
\text { de subsídios encontrados no } \\
\text { referencial teórico da bioética de } \\
\text { proteçâ, acreditamos que os } \\
\text { currículos médicos e os cursos de } \\
\text { Bioética deveriam criar espaços } \\
\text { para abordar essa temática, } \\
\text { empregando diferentes práticas } \\
\text { pedagógicas efetivamente } \\
\text { transformadoras, e respeitando a } \\
\text { diversidade de gênero em todos } \\
\text { os ambientes. }\end{array}$ \\
\hline $2 I$. & $\begin{array}{l}\text { Internacionalização do ensino } \\
\text { superior e os impactos da }\end{array}$ & 2019 & $\begin{array}{c}\text { Revista } \\
\text { Avaliação }\end{array}$ & $\begin{array}{l}\text { da|Revisão } \\
\text { da|Bibliográfica }\end{array}$ & $\begin{array}{l}\text { Há necessidade de programas de } \\
\text { acolhimento e integração dos }\end{array}$ \\
\hline
\end{tabular}




\begin{tabular}{|c|c|c|c|c|c|}
\hline & $\begin{array}{l}\text { imigração na saúde mental de } \\
\text { estudantes internacionais. }\end{array}$ & & $\begin{array}{l}\text { Educação } \\
\text { Superior }\end{array}$ & & $\begin{array}{l}\text { estudantes internacionais, que } \\
\text { possibilitem minimizar o } \\
\text { impacto migratório inicial, e } \\
\text { assim colaborar para a } \\
\text { adaptação socioeducacional do } \\
\text { estudante. }\end{array}$ \\
\hline 22. & $\begin{array}{l}\text { Juventude universitária e } \\
\text { direitos de cidadania: sentidos } \\
\text { atribuídos à diversidade sexual. }\end{array}$ & 2018 & $\begin{array}{l}\text { Cadernos } \\
\text { Pesquisa }\end{array}$ & Quantitativo & $\begin{array}{l}\text { Evidenciado alto grau de } \\
\text { aceitação da homossexualidade. } \\
\text { No entanto, essa aceitação } \\
\text { declina quando se coloca em } \\
\text { questão a convivência com } \\
\text { pessoas homossexuais e, quando } \\
\text { se aborda o apoio aos seus } \\
\text { direitos de cidadania. Com isso, } \\
\text { percebemos, que mudanças no } \\
\text { sistema da heteronormatividade, } \\
\text { ainda são superficiais. }\end{array}$ \\
\hline 23. & $\begin{array}{l}\text { A sexualidade nos cursos de } \\
\text { licenciatura e a interface com } \\
\text { políticas de formação de } \\
\text { professores/as. }\end{array}$ & 2018 & $\begin{array}{l}\text { Educação } \\
\text { Pesquisa }\end{array}$ & $\begin{array}{l}\text { elAnálise } \\
\text { documental }\end{array}$ & $\begin{array}{l}\text { Dentre os cursos de graduação, a } \\
\text { pedagogia emergiu como o campo } \\
\text { de saber privilegiado para as } \\
\text { discussões da sexualidade, pois } \\
\text { constitui-se em número } \\
\text { significativo de disciplinas } \\
\text { relacionadas à temática. } \\
\text { Enquanto as políticas } \\
\text { educacionais, têm impulsionado o } \\
\text { debate acerca da diversidade eda } \\
\text { diferença, tornando-se pauta de } \\
\text { debate nas ementas das } \\
\text { disciplinas. Assim, foi possível } \\
\text { refletir, os deslocamentos que o } \\
\text { dispositivo da sexualidade vem } \\
\text { sofrendo na contemporaneidade. }\end{array}$ \\
\hline 24. & $\begin{array}{l}\text { Formação de formadores e suas } \\
\text { significações para a educação } \\
\text { inclusiva. }\end{array}$ & 2018 & $\begin{array}{l}\text { Educação } \\
\text { Pesquisa }\end{array}$ & Qualitativo & $\begin{array}{l}\text { Foi evidenciado, que a formação } \\
\text { dos formadores, é pouca ou } \\
\text { nenhuma, no que se refere à } \\
\text { inclusão escolar e à } \\
\text { aprendizagem de alunos com } \\
\text { necessidades educacionais } \\
\text { especiais. As barreiras } \\
\text { atitudinais também puderam ser } \\
\text { notadas, demonstrando que esse é } \\
\text { umproblemaque estálonge de ser } \\
\text { ultrapassado, e configura um } \\
\text { entrave para o sucesso do } \\
\text { processo inclusivo. }\end{array}$ \\
\hline 25 . & $\begin{array}{l}\text { Multiculturalismo e formação } \\
\text { de professores: dimensões, } \\
\text { possibilidades e desafios na } \\
\text { contemporaneidade. }\end{array}$ & 2018 & $\begin{array}{l}\text { Ensaio: } \\
\text { Avaliação } \\
\text { Políticas } \\
\text { Públicas } \\
\text { Educação }\end{array}$ & eEnsaio & $\begin{array}{l}\text { O multiculturalismo não deve ser } \\
\text { tratado como um adendo ao } \\
\text { currículo ou perspectiva reduzida } \\
\text { a projetos extracurriculares; é } \\
\text { relevante considerar modos pelos }\end{array}$ \\
\hline
\end{tabular}




\begin{tabular}{|c|c|c|c|c|c|}
\hline & & & & & $\begin{array}{l}\text { quais a construção curricular } \\
\text { poderia articular a perspectiva } \\
\text { multicultural aos diferentes } \\
\text { campos de saber e disciplinas que } \\
\text { constituem o currículo de } \\
\text { formação de professores }\end{array}$ \\
\hline 26. & $\begin{array}{l}\text { Ideologia de gênero: uma falácia } \\
\text { construída sobre os planos de } \\
\text { educação brasileiros. }\end{array}$ & 2017 & $\begin{array}{l}\text { Educação } \\
\text { Sociedade }\end{array}$ & Reflexão & $\begin{array}{l}\text { Há necessidade do envolvimento } \\
\text { de outros setores, a fim de } \\
\text { diminuir o enviesamento, e } \\
\text { contribuir para que a Educação } \\
\text { brasileira incorpore a igualdade } \\
\text { de gênero e o respeito à } \\
\text { diversidade sexual. }\end{array}$ \\
\hline 27. & $\begin{array}{l}\text { Cidadania, reconhecimento } e \\
\text { ação afirmativa no ensino } \\
\text { superior. }\end{array}$ & 2015 & $\begin{array}{lr}\text { Civitas } \\
\text { Revista } \\
\text { Ciências } & \text { Sociais }\end{array}$ & $\begin{array}{l}\text { Análise } \\
\text { documental }\end{array}$ & $\begin{array}{l}\text { Em período de dez anos, mais de } \\
70 \% \text { das universidades públicas } \\
\text { enfrentaram desafios para sua } \\
\text { transformação em uma } \\
\text { instituiçâa que incorpore a ideia } \\
\text { do direito social, do acesso à } \\
\text { educação de forma mais } \\
\text { substantiva. }\end{array}$ \\
\hline 28. & $\begin{array}{l}\text { Educar para a diversidade: } \\
\text { gênero e sexualidade segundo a } \\
\text { percepção de estudantes e } \\
\text { supervisoras do programa } \\
\text { institucional de bolsa de } \\
\text { iniciação à docência (UFSM). }\end{array}$ & 2015 & $\begin{array}{c}\text { Revista da } \\
\text { Educação Física }\end{array}$ & Qualitativo & $\begin{array}{l}\text { Há associação, entre os conceitos } \\
\text { de gênero e sexualidade, cujas } \\
\text { explicitações mantêm forte } \\
\text { relação com aspectos biológicos } \\
\text { do corpo, e estão assentadas } \\
\text { quase que exclusivamente em } \\
\text { heteronormativas. }\end{array}$ \\
\hline 29. & $\begin{array}{l}\text { Políticas curriculares da } \\
\text { internacionalização do ensino } \\
\text { superior: multiculturalismo ou } \\
\text { semiformação? }\end{array}$ & 2011 & \begin{tabular}{l}
\multicolumn{1}{|c}{ Ensaio: } \\
Avaliação \\
Políticas \\
Públicas \\
Educação
\end{tabular} & Ensaio & $\begin{array}{l}\text { Ao invés da promoção da } \\
\text { diversidade cultural, tem-se a } \\
\text { defesa de uma forma particular } \\
\text { de cultura, que busca sua } \\
\text { legitimação por meio da } \\
\text { padronização curricular nos } \\
\text { cursos, dos idiomas e das } \\
\text { experiências culturais. }\end{array}$ \\
\hline
\end{tabular}

Fonte: Elaboração dos autores, 2020.

\section{Conclusão}

Há necessidade do despertar, de todas as ciências, para reflexões acerca da abordagem das diversidades no ambiente universitário, para maior sensibilização ao estado da arte, redução das desigualdades de acesso e inclusão, qualidade da permanência em âmbito da saúde integral, e do processo de ensino e aprendizagem, e melhor qualidade de vida acadêmica. 


\section{Referências}

AFONSO, Maria Lúcia Miranda; RODRIGUES, Maximiliano; OLIVEIRA, Eduardo Francisco. Juventude universitária e direitos de cidadania: sentidos atribuídos à diversidade sexual. Cadernos de Pesquisa, v. 48, n. 169, 2018.

ANDRES, Suélen de Souza; JAEGER, Angelita Alice; GOELLNER, Silvana Vilodre. Educar para a diversidade: gênero e sexualidade segundo a percepção de estudantes e supervisoras do programa institucional de bolsa de iniciação à docência (UFSM). Revista da Educação Física / UEM, v. 26, n. 2, 2015.

ANDRES, Suélen de Souza; JAEGER, angelita Alice; GOELLNER, Silvana Vilodre. Educar para a diversidade: gênero e sexualidade segundo a percepção de estudantes e supervisoras do programa institucional de bolsa de iniciação à docência (UFSM). Revista da Educação Física / UEM , v. 26, n. 2, 2015.

BARBOSA, Matheus Ghossain; SILVA, Magnus Régios Dias da; SERÓDIO, Aluísio Marçal de Barros. Transgender Population under the Bioethics Perspective: a Panorama of the Curricula and Bioethics Courses of Medical Schools of the State of São Paulo. Revista Brasileira de Educação Médica, v. 44, n. 3, 2020.

BAZON, Fernanda Vilhena Mafra et al. Formação de formadores e suas significações para a educação inclusiva. Educação e Pesquisa, v. 44, 2018.

BISOL, Cláudia Alquati. Estratégias de pesquisa em contextos de diversidade cultural: entrevistas de listagem livre, entrevistas com informantes-chave e grupos focais. Rev. Estudos de Psicologia (Campinas), v. 29, 2012.

BRAH, Avtar. Diferença, diversidade, diferenciação. Cadernos pagu (26), jan-jun., 2006.

BRASIL. Lei no 12.711 , de 29 de agosto de 2012. Dispõe sobre o ingresso nas universidades federais e nas instituições federais de ensino técnico de nível médio e dá outras providências. Disponível em: http://www.planalto.gov.br/ccivil_03/_ato2011-2014/2012/lei/li27II.htm.

BRASIL. Lei no 13.146, de 6 de julho de 2015. Institui a Lei Brasileira de Inclusão da Pessoa com Deciência (Estatuto da Pessoa com Deficiência). Disponível em: http://www.planalto.gov.br/ccivil_03/_ato2015-2018/2015/lei/li3146.htm.

FERNANDES, Helane de Fátima Gomes; ANDRADE, Ana Isabel. Formação de professores para a justiça social: uma revisão de estudos empíricos. Educação em Revista, v. 36, 2020.

FERRI, Erika Kaneta; BAGNATO, Maria Helena. Políticas públicas de Ação Afirmativa para indígenas na Universidade Estadual de Mato Grosso do Sul: a visão dos implementadores. ProPosições, v. 29, n. I, 2018.

GUIMARÃES, Nadya Araujo; ANDRADA, Ana Carolina; PICANÇO, Monise Fernandes. Transitando entre universidade e trabalho: trajetórias desiguais e políticas afirmativas. Cadernos de Pesquisa, v. 49, n. 172, 2019.

HUISMAN, Jeroen. Differentiation, diversity and dependency in higher education: a 
theoretical and empirical analysis. Utrecht, Management and Policy in Higher Education, 1995.

IVENICKI, Ana. Multiculturalismo e formação de professores: dimensões, possibilidades e desafios na contemporaneidade. Ensaio: Avaliação e Políticas Públicas em Educação, v. 26, n. IOo, 2018.

JESUS, Jaqueline Gomes de. O desafio da convivência: assessoria de diversidade e apoio aos cotistas (2004-2008). Psicologia: Ciência e Profissão, v. 33, n.I, 2013.

LIMA, Manolita Correia; MARANHAO, Carolina Saraiva de Albuquerque. Políticas curriculares da internacionalização do ensino superior: multiculturalismo ou semiformação? Ensaio: Avaliação e Políticas Públicas em Educação. Ensaio: aval.pol.públ.Educ. [online]. 2oII, v. 19, n. 72, 2011.

LOPES, Jorge. Fazer do Trabalho Científico em Ciências Sociais Aplicadas. Recife: Editora Universitária UFPE, 2006.

LOPES, Yéssica; JUNQUEIRA, Rogério. Conceitos de Diversidade Parte I. Rev. Diversidade e Educação, v.2, n.3, p. 4-II, jan./jun., 20I4.

MELLO, Luciana Garcia de. Da crítica à política: Tensões entre reconhecimento e democracia racial na política de cotas da Ufrgs. Civitas - Revista de Ciências Sociais, v. 17, n. 2, 2017.

MENEZES, Jaileila Araújo; LINS, Saiane Silva; SAMPAIO, Juliana Vieira. Provocações PósColoniais à Formação Em Psicologia. Rev., Psicologia \& Sociedade, v.3I, 2019.

MOCELIN, Cassia Engres. Uma análise marxiana da política de cotas no ensino superior público brasileiro. Revista Katálysis, v. 23, n. I, jan-abril, 2020.

MORETTI-PIRES et al. Preconceito contra Diversidade Sexual e de Gênero entre Estudantes

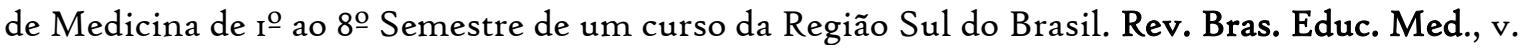
43, n. I, 2019.

NOBREGA, Maria Helena da. Intercâmbios educacionais e diversidade cultural: implicações para o ensino de português para falantes de outras línguas. Revista Brasileira de Linguística Aplicada, v. 14, n. I, 2014.

PAIVA, Angela Randolpho. Cidadania, reconhecimento e ação afirmativa no ensino superior. Civitas - Revista de Ciências Sociais, v. 15, n. 4, 2015.

REIS, Toni; EGGERT, Edla. Ideologia de Gênero: Uma Falácia Construída Sobre os Planos de Educação Brasileiros. Educação \& Sociedade, v. 38, n. 138, 2017.

RIZZA, Juliana Lapa; RIBEIRO, Paula Regina Costa; MOTA, Maria Renata Alonso. A sexualidade nos cursos de licenciatura e a interface com políticas de formação de professores/as. Educação e Pesquisa, v. 44, 2018.

SANTOS, Fernanda Batista, et al. Black women in nursing history: the cultural competence in Maria Barbosa Fernandes' trajectory .Revista Brasileira de Enfermagem, v.73, 2020. 
SILVA, Ani Martins; CYMROT, Raquel; D’ANTINO, Maria Eloisa Famá. Demandas de docentes do ensino superior para a formação de alunos com deficiência. Revista Brasileira de Estudos Pedagógicos, v. 93, n. 235, 2012.

SILVA, Bruno Santana da; ANDRADE, Adja Ferreira de. Análise Descritiva do Tema Deficiência nos Currículos de Graduação da Universidade Federal do Rio Grande do Norte. Rev. bras. educ. espec., v. 25, n.3, 2019.

SILVA, Márcia Alves. A incorporação da temática de gênero e diversidade na academia: por uma ecologia de saberes na universidade. Educar em Revista, v. 34 n. 70, 2018.

SILVA-FERREIRA, Alisson Vinícius; MARTINS-BORGES, Lucienne; WILLECKE, Thiago Guedes. Internacionalização do ensino superior e os impactos da imigração na saúde mental de estudantes internacionais. Revista da Avaliação da Educação Superior (Campinas), v. 24, n. 3, 2019 .

SOUZA, Alberto de Mello. Desempenho dos candidatos no vestibular e o sistema de cotas na UERJ. Ensaio: Avaliação e Políticas Públicas em Educação. Ensaio: aval.pol.públ.Educ. [online], v. 20, n. 77, 2012.

SOUZA, Leandro Corsico; DINIS, Nilson Fernandes. Discursos sobre homossexualidade e gênero na formação docente em biologia. Rev. Pro-Posições, v. 2I, n. 3, 2010.

TAVARES, Manuel; GOMES, Sandra. Fundamentos epistemológicos da matriz institucional dos novos modelos de educação superior no brasil: uma abordagem qualitativa dos documentos institucionais da universidade federal DO ABC. Rev. Educação \& Sociedade, v 39, n. 44, 2017.

VERA, Ivania; AVERSI-FERREIRA, Tales Alexandre; LUCCHESE, Roselma. A experiência do professor orientador de estudante indígena em enfermagem. Rev.Acta Paulista de Enfermagem, v. 24, n. 2, 2011. 